\title{
Roles of C-Repeat Binding Factors-Dependent Signaling Pathway in Jasmonates-Mediated Improvement of Chilling Tolerance of Postharvest Horticultural Commodities
}

\author{
Libin Wang $\mathbb{D},{ }^{1,2}$ Xiuxiu Sun, ${ }^{2,3}$ Weiqi Luo, ${ }^{2}$ and Chunlu Qian $\mathbb{D}^{4}$ \\ ${ }^{1}$ State Key Laboratory of Crop Genetics and Germplasm Enhancement, Nanjing Agricultural University, Nanjing, \\ Jiangsu 210095, China \\ ${ }^{2}$ Horticultural Research Laboratory, ARS, USDA, Fort Pierce, FL 34945, USA \\ ${ }^{3}$ Indian River Research and Education Center, University of Florida, Fort Pierce, FL 34845, USA \\ ${ }^{4}$ College of Food Science and Engineering, Yangzhou University, Yangzhou, Jiangsu 225127, China \\ Correspondence should be addressed to Libin Wang; wanglibin@njau.edu.cn
}

Received 23 October 2017; Revised 30 November 2017; Accepted 13 December 2017; Published 8 March 2018

Academic Editor: Elena González-Fandos

Copyright (c) 2018 Libin Wang et al. This is an open access article distributed under the Creative Commons Attribution License, which permits unrestricted use, distribution, and reproduction in any medium, provided the original work is properly cited.

\begin{abstract}
C-repeat binding factor- (CBF-) dependent signaling pathway is proposed to be a key responder to low temperature stress in plant. Jasmonates (JAs), the endogenous signal molecules in plant, participate in plant defense against (a)biotic stresses; however, the mechanism has not been fully clarified so far. With the progress made in JAs biopathway, signal transduction, and their relationship with CBF-dependent signaling pathway, our knowledge of the roles of the CBF-dependent signaling pathway in JAs-mediated improvement of chilling tolerance accumulates. In this review, we firstly briefly review the chilling injury (CI) characteristics of postharvest horticultural commodities, then introduce the biopathway and signal transduction of JAs, subsequently summarize the roles of the CBF-dependent signaling pathway under low temperature stress, and finally describe the linkage between JAs signal transduction and the CBF-dependent signaling pathway.
\end{abstract}

\section{Introduction}

Preservation, transportation, and marketing of postharvest horticultural commodities at low temperatures constitute the main strategy employed in food industries to retard quality deterioration [1]. However, upon exposure to low temperatures ranging from 0 to $15^{\circ} \mathrm{C}$, a series of physiological and biochemical alternations is initiated in some horticultural commodities of tropical/subtropical origin, leading to the development of chilling injury (CI) and a great economical loss [2-5].

During low temperature stress, cold signal is perceived by undefined sensor in membrane prior to the activation of several cold signaling pathways [6]. In the promoters of these genes, there are cis-elements termed C-repeat elements/dehydration-responsive elements (CRT/DRE), where $\mathrm{C}$-repeat binding factors (CBFs) bind [7]. CBFs, which participate in transcriptional regulation of low temperature acclimation [6], are under the positive control of the upstream
Inducer of CBF Expression (ICE), including ICE1 and ICE2 [8]. Activation of CBF-dependent signaling pathway, particularly the ICE1-CBF transcriptional cascade, is proposed to be a key response to low temperature stress in plant, enhancing their chilling resistance $[6,9]$. Three CBFs, which are involved in low temperature stress, have been identified in Arabidopsis, including AtCBF1, AtCBF2, and AtCBF3 [10]. Overexpression of $A t C B F 2$ results in the induction of 85 coldregulated (COR) genes in Arabidopsis [11].

Jasmonic acid and its derivatives, collectively referred to as jasmonates (JAs), are ubiquitous plant hormone [12]. Besides functioning in plant growth and developmental process, JAs play important roles in plant defense against a variety of (a)biotic stresses, such as pathogens [13], herbivory [14], mechanical wounding [15], low temperature [16], and high salinity [17].

The roles of JAs in alleviating the CI of postharvest horticultural commodities have been the focus of research for many years. Upon exposure to (a)biotic stresses, the increase 
of endogenous JAs precedes the activation of JAs-mediated defense [18]; meanwhile, the application of exogenous JAs at proper concentrations could effectively ameliorate CI symptoms of postharvest horticultural commodities, such as papaya, avocado, banana, and tomato (Table 2), and this effect might be due to the activation of various physiological and biochemical responses [19]. However, this mechanism has not yet been fully clarified. With the aid of new technologies, our knowledge on JAs biosynthesis, signal transduction, and their relationship with CBF-dependent signaling pathway expands. In this review, we firstly briefly review the CI characteristic of postharvest horticultural commodities, then introduce the biopathway and signal transduction of JAs, subsequently summarize the roles of CBF-dependent signaling pathway during the low temperature stress, and finally describe the linkage between JAs signal transduction and the CBF-dependent signaling pathway. This review would provide a deeper understanding on the mechanism employed by prechilling JAs treatment to mitigate CI of postharvest horticultural commodities.

\section{CI Characteristics of Postharvest Horticultural Commodities}

2.1. CI Symptoms and Impact Factors. Exposure of horticultural commodities of tropical/subtropical origin to low temperature ranging from 0 to $15^{\circ} \mathrm{C}$ would initiate a series of physiological and biochemical alternations, leading to the development of various CI symptoms [2-4], which can be categorized into two groups: (1) developmental or metabolic symptoms with qualitative nature and (2) physiological symptoms, including pitting, discoloration, water soaking, internal breakdown, susceptibility to mechanical injury, and fungal attack [2]. Table 1 lists CI symptoms of several horticultural commodities along with their critical chilling temperatures [1].

Many factors can impact the chilling susceptibility of horticultural commodities, including the genotype, ripening stage, metabolic status, and other environmental conditions [20]. For example, green and breaker tomato fruits $(<10 \% \mathrm{red}$ coloration, USDA 1976) are more susceptible to low temperature stress than fruits at red-ripe stage [21]. A more severe CI phenomenon was observed in horticultural commodities subjected to lower environmental temperatures. Additionally, the duration of chilling exposure is positively correlated with CI index [22].

However, it is the genetic makeup that determines to what degree a species or cultivar is sensitive or resistant to low temperature stress [23]. Arabidopsis with higher expression level of $A t C B F 3$ demonstrates an enhanced chilling tolerance [24].

\subsection{Physiological and Biochemical Alternations Resulting} in the Development of Visual CI. The cell membrane is the primary cellular structure affected by low temperature stress [55]. The transition of cell membrane from a liquidcrystalline phase to a solid-gel structure during chilling stress causes the loss of membrane semipermeability, the dysfunction of membrane proteins, the increase of free cytosolic calcium, and the cessation of protoplasmic streaming, which is followed by the electrolyte leakage, energy supply reduction, and an increase in susceptibility to oxidative stress [55, 56] (Figure 1). If there is exposure to chilling stress for a longer time, further responses could be initiated along with the rupture of cell membrane, presenting as various visual CI symptoms such as pitting, water soaking, and decay $[3,4]$ (Figure 1).

\section{Biopathway and Signal Transduction of JAs}

3.1. JAs Biosynthetic Pathway. As shown in Figure 2, JAs biosynthesis is initiated by a phospholipase-mediated release of $\alpha$-linolenic acid in chloroplast, which is then oxidized by TomloxD into 13(S)-hydroperoxylinolenic acid (13-HPOT) $[57,58]$. The latter is further oxidized and cyclized into cis(+)-12-oxophytodienoic acid (cis-(+)-OPDA) by the actions of allene oxide synthase (AOS) and allene oxide cyclase (AOC) [59]. Subsequently, cis-(+)-OPDA is transported by COMATOSE1/PEROXIMAL1/PEROXISOME ABC TRANSPORTER (ABC CTS1/PXA1/PED3) or ion trapping from the chloroplast to the peroxisome [58], where cis-(+)-OPDA is oxidized and then esterified before three rounds of $\beta$ oxidation with the generation of (+)-7-iso-JA [60]. The core enzymes for $\beta$-oxidation include acyl CoA oxidase (ACX), multifunctional protein (MFP), and 3-ketoacyl-CoA thiolase (KAT) [61]. Upon synthesis, the (+)-7-iso-JA is immediately epimerized to (-)-JA and further converted into various derivatives, such as methyl jasmonate (MeJA) and jasmonoyl-isoleucine (JA-Ile) [58, 62] (Figure 2). In plant, a small amount of JAs is derived from hexadecatrienoic acid [63].

JAs biosynthesis in plant is regulated by various factors, like substrate availability, JASMONATE-ZIM-DOMAIN (JAZ) protein, $\mathrm{Ca}^{2+} /$ mitogen-activated protein kinase (MAPK) cascades, and so on [19]. Among several branches known for the LOX pathway, the AOS and hydroperoxide lyase (HPL) branches are concurrent on the same substrate, 13-HPOT [19]. The HPL branch leads to the generation of green leaf volatiles (GLVs), which are defense compounds formed upon herbivore attack $[64,65]$. Mutation of OsHPL3 would reduce wound-induced GLV emission but increase JAs accumulation [66]. For more information relevant to the regulation of JAs biosynthesis, readers could refer to the review written by Wasternack and Hause [19].

3.2. JAs Signal Transduction. Recently, JA-Ile has been identified as the bioactive compound in JAs signaling [12]. Along with this discovery, other breakthroughs relevant to JAs signal transduction have been made, such as the identification of JAZ repressors $[67,68]$ and CORONATINE INSENSITIVE1JAZ (COI1-JAZ) coreceptor [69].

Figure 3 summarizes the primary signal transduction process after its perception [58, 71, 72]: in the absence of JA-Ile, JAZ repressors suppress transcription factors (TFs) such as bHLHzip transcription factors (MYCs) by recruiting the corepressors TOPLESS (TPL) and TPLrelated proteins via the adaptor protein, Novel Interactor 
TABLE 1: Chilling injury (CI) symptoms of several horticultural commodities with their critical chilling temperatures [1].

\begin{tabular}{|c|c|c|}
\hline Horticultural commodity & Critical chilling temperature $\left({ }^{\circ} \mathrm{C}\right)$ & CI symptom when stored between $0^{\circ} \mathrm{C}$ and safe temperature \\
\hline Apple, certain cultivars & $2-3$ & Internal browning, brown core, soggy breakdown, soft scald \\
\hline Asparagus & $0-2$ & Dull, gray-green, limp tips \\
\hline Atemoya & 4 & Skin darkening, failure to ripen, pulp discoloration \\
\hline Avocado & $4.5-13$ & Grayish-brown discoloration of flesh \\
\hline Bael & 3 & Brown spots on skin \\
\hline Banana, green or ripe & $11.5-13$ & Dull color when ripened \\
\hline Bean (lima) & $1-4.5$ & Rusty brown specks, spots, or areas \\
\hline Bean (snap) & 7 & Pitting and russeting \\
\hline Breadfruit & $7-12$ & Abnormal ripening, dull brown discoloration \\
\hline Chayote & $5-10$ & Dull brown discoloration, pitting, flesh darkening \\
\hline Cranberry & 2 & Rubbery texture, red flesh \\
\hline Cucumber & 7 & Pitting, water-soaked spots, decay \\
\hline Eggplant & 7 & Surface scald, Alternaria rot, blackening of seeds \\
\hline Ginger & 7 & Softening, tissue breakdown, decay \\
\hline Guava fruit & 4.5 & Pulp injury, decay \\
\hline Grapefruit & 10 & Scald, pitting, watery breakdown \\
\hline Jicama & $13-18$ & Surface decay, discoloration \\
\hline Lemon & $11-13$ & Pitting, membranous staining, red blotch \\
\hline Lime & $7-9$ & Pitting, turning tan with time \\
\hline Lychee & 3 & Skin browning \\
\hline Mango fruit & $10-13$ & Grayish scald-like discoloration of skin, uneven ripening \\
\hline Mangosteen & $4-8$ & Hardening and browning of the cortex \\
\hline \multicolumn{3}{|l|}{ Melon } \\
\hline Cantaloupe & $2-5$ & Pitting, surface decay \\
\hline Honeydew & $7-10$ & Reddish-tan discoloration, pitting, surface decay, failure to ripen \\
\hline Casaba & $7-10$ & The same as above but no discoloration \\
\hline Crenshaw and Persian & $7-10$ & The same as above but no discoloration \\
\hline Okra pod & 7 & Discoloration, water-soaked areas, pitting, decay \\
\hline Olive, fresh & 7 & Internal browning \\
\hline Orange & 3 & Pitting, brown stain \\
\hline Papaya & 7 & Pitting, failure to ripen, off-flavor, decay \\
\hline Passion fruit & 10 & Dark red discoloration on skin, loss of flavor, decay \\
\hline Pepper, sweet & 7 & Sheet pitting, Alternaria rot on pods and calyxes, darkening of seed \\
\hline Pineapple & $7-10$ & Dull green when ripened \\
\hline Pomegranate & 4.5 & Pitting, external and internal browning \\
\hline Potato & 3 & Mahogany browning (Chippewa and Sebago), sweetening \\
\hline Pumpkin and hard-shell squash & 10 & Decay, especially Alternaria rot \\
\hline Rambutan & 10 & Darkening of exocarp \\
\hline Sweet potato & 13 & Decay, pitting, internal discolorations; hardcore when cooked \\
\hline Tamarillo & $3-4$ & Surface pitting, discoloration \\
\hline \multicolumn{3}{|l|}{ Tomato } \\
\hline Ripe & $7-10$ & Water soaking and softening, decay \\
\hline Mature green & 13 & Poor color when ripe, Alternaria rot \\
\hline Water convolvulus & 10 & Darkening of leaves and stems \\
\hline Watermelon & 4.5 & Pitting, objectionable flavor \\
\hline
\end{tabular}

of JAZ (NINJA), and thus suppress the expression of JAsregulated genes. On the other hand, during plant development or (a)biotic stresses when JA-Ile levels are high, a F-box protein COIl, which is an integral part of the Skp-Cullin-F-box (SCF) complex, targets JAZ repressors by the aid of inositol pentakisphosphate 5 (IP5) for polyubiquitination; JAZ repressors are subsequently degraded by a $26 \mathrm{~S}$ ubiquitin-proteasome system, thus relieving TFs blockage and activating the gene expression downstream [19, 73]. The initiation of transcription also needs the recruitment 


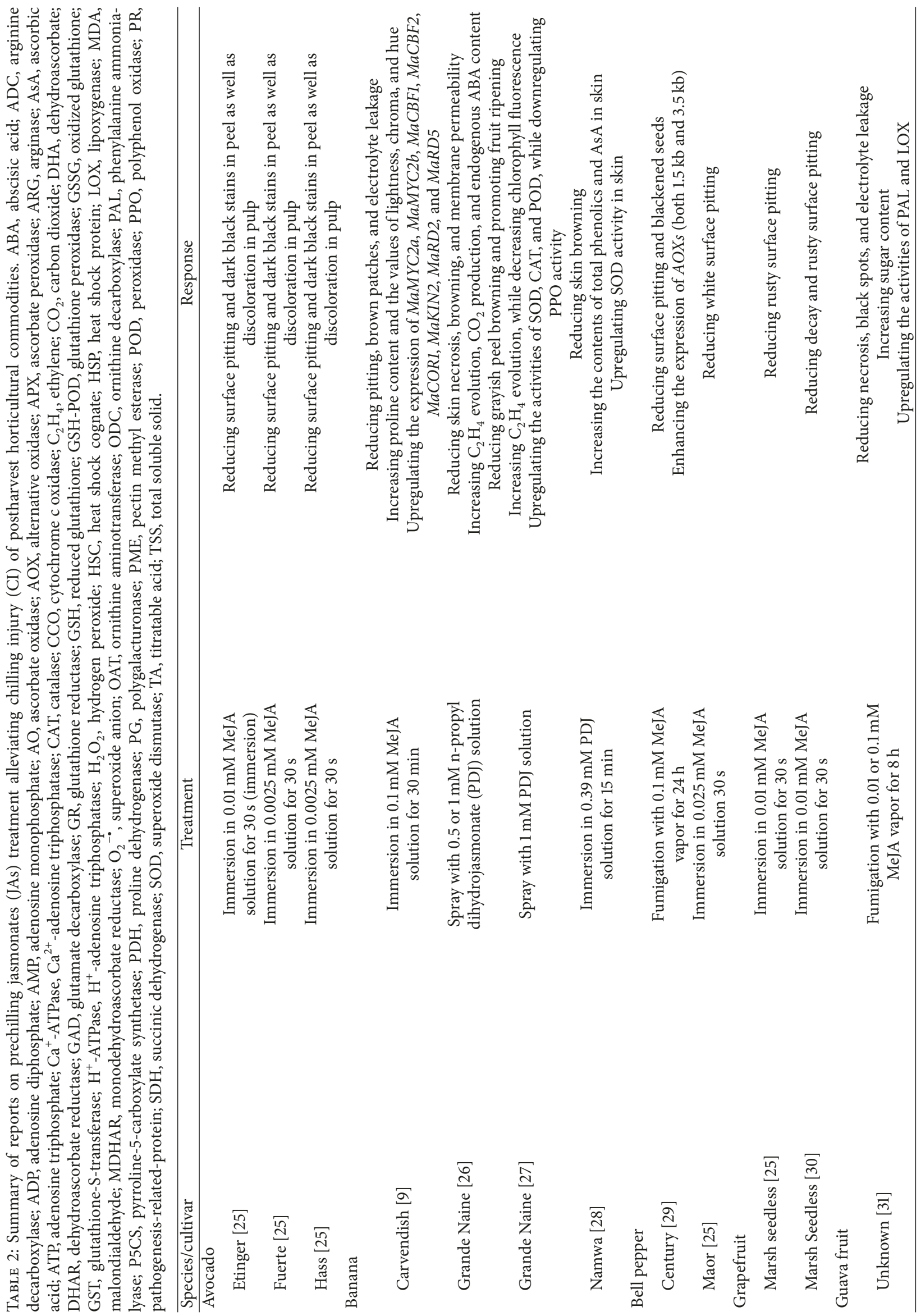




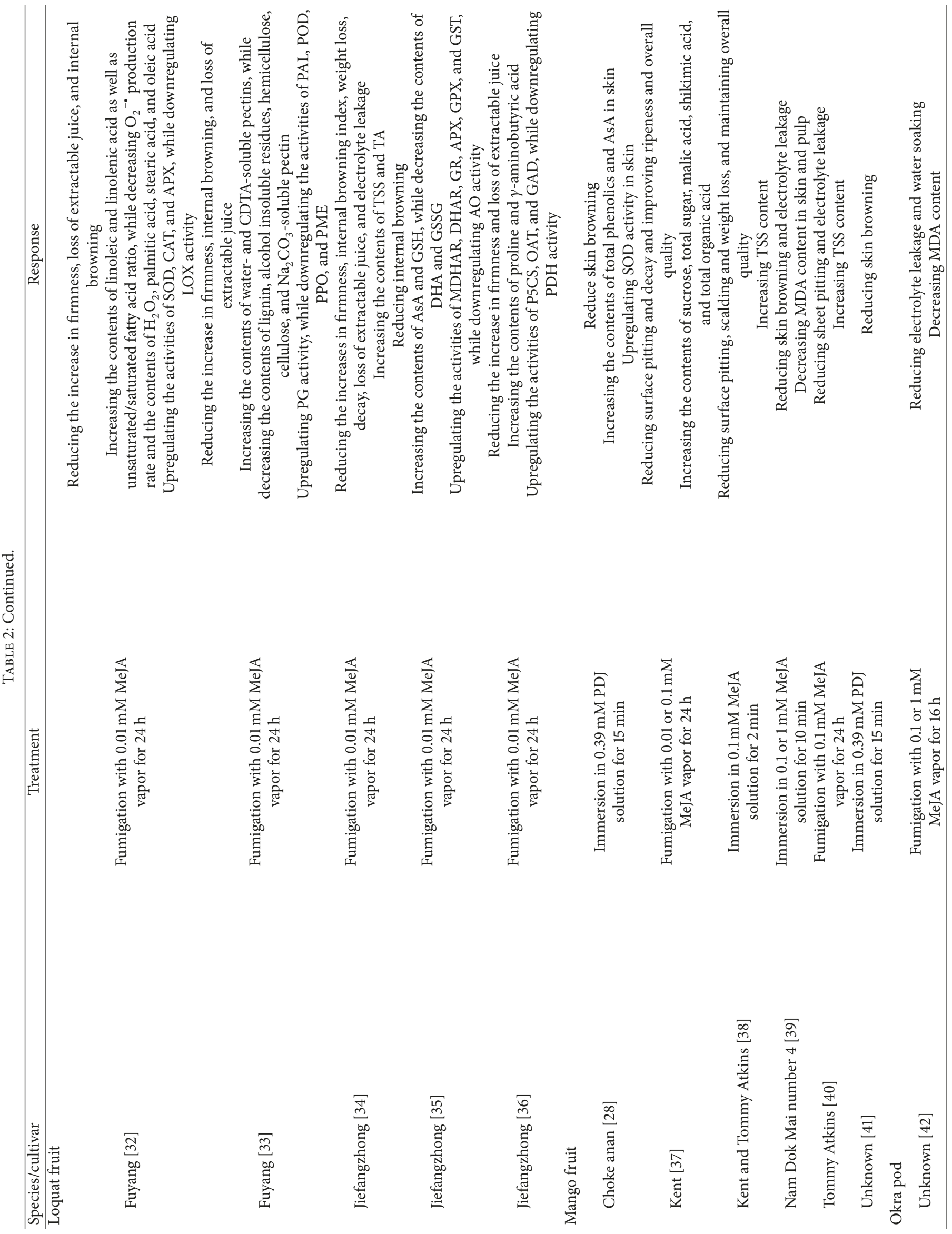




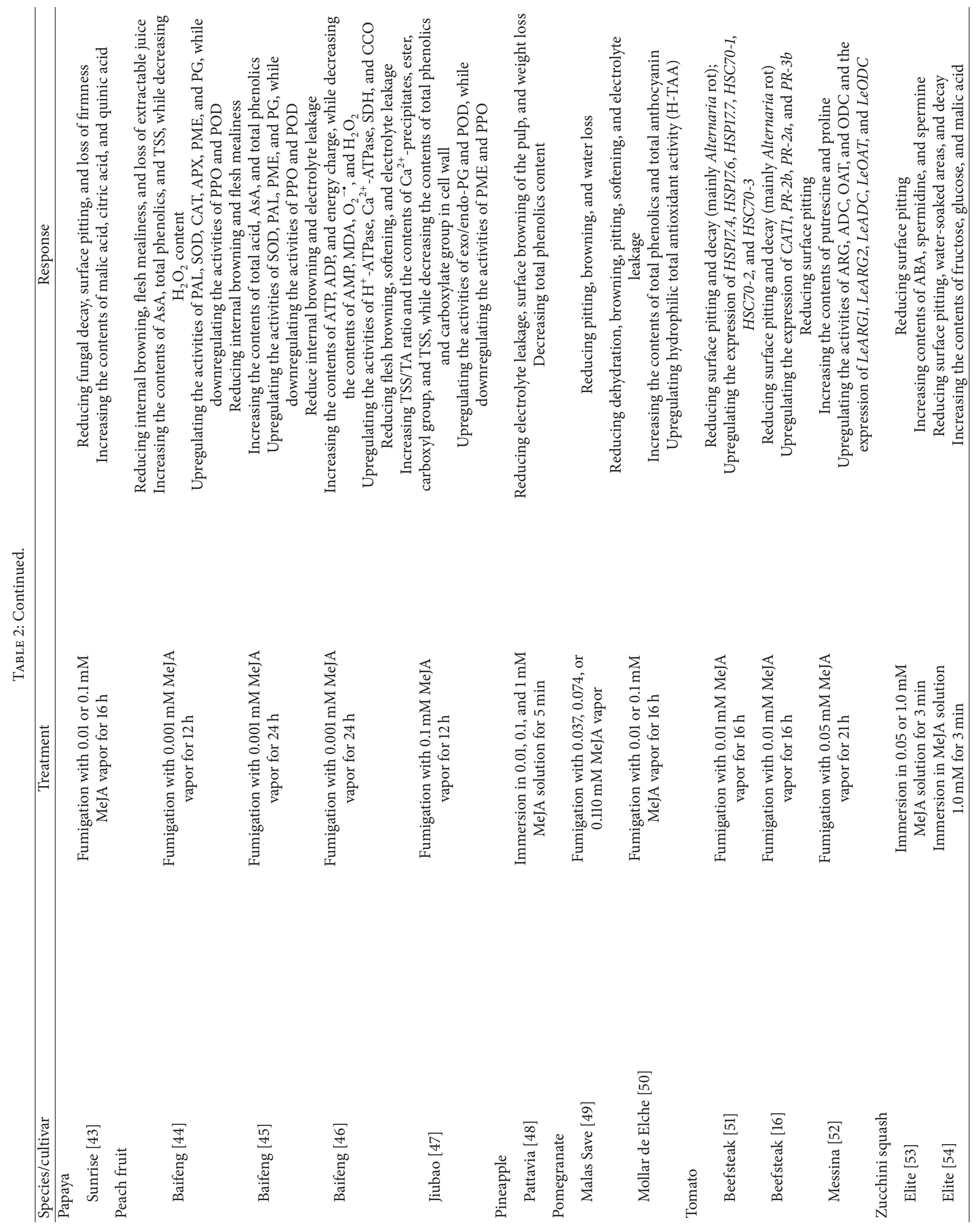




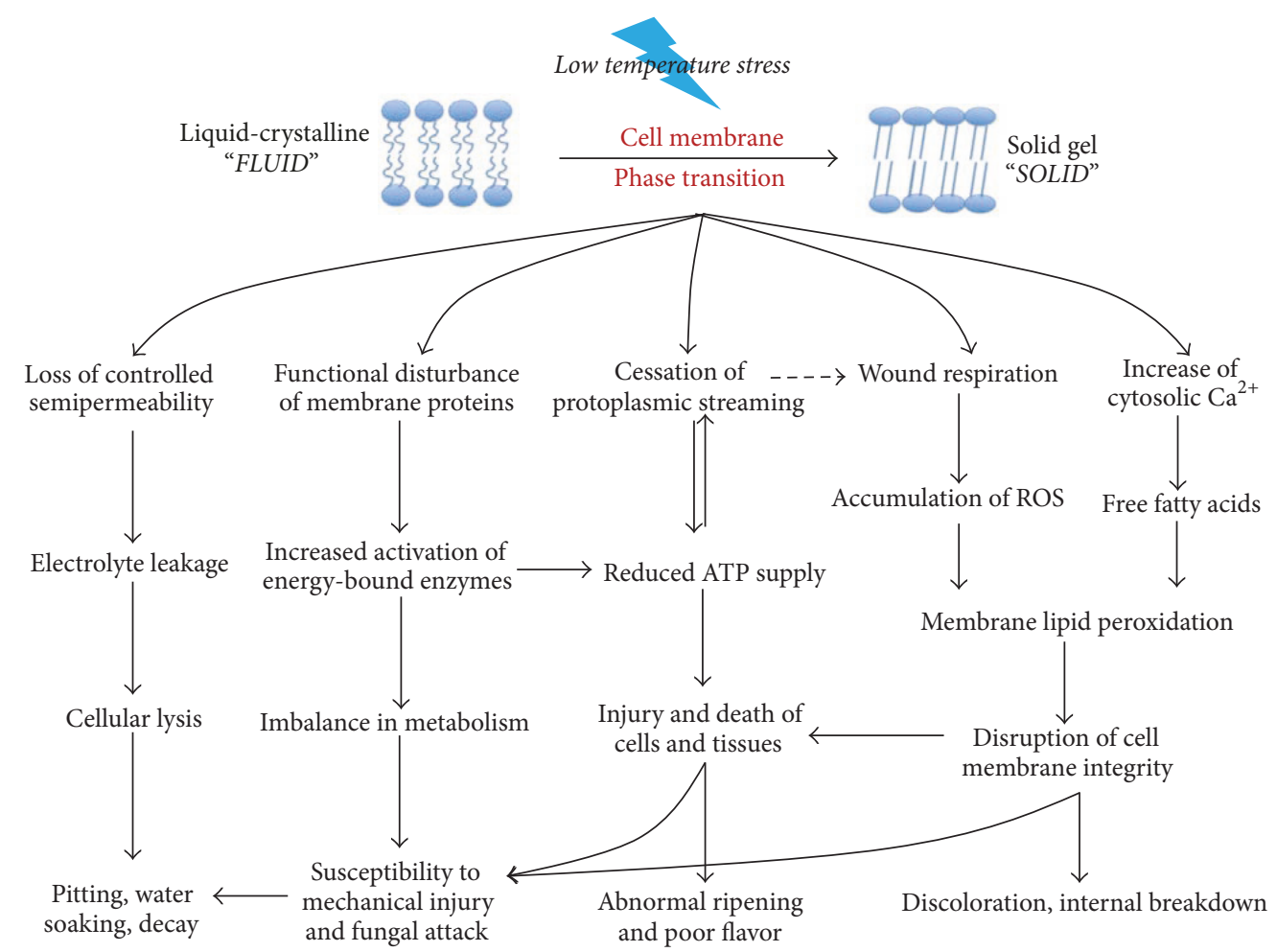

FIGURE 1: Possible physiological and biochemical mechanisms of chilling injury symptoms in postharvest horticultural commodities [2, 70].

of general transcription factors (GTFs) and RNA polymerase II to TFs-bound promoter through the interaction of TFs and MEDIATOR25 (MED25) subunit of Mediator complex [71] (Figure 3).

\section{Exogenous Application of JAs to Reduce CI of Postharvest Horticultural Commodities}

Upon exposure to (a)biotic stresses, the increase of endogenous JAs precedes the activation of JAs-mediated defense [18]. A higher level of endogenous JA was observed in the skin of mangosteen during early storage at $7^{\circ} \mathrm{C}$ [41], which agreed with the finding in apple fruitlet [74]. These results imply a role of JAs in low temperature stress of postharvest horticultural commodities. Table 2 lists the reports on exogenous JAs application ameliorating CI symptoms of postharvest horticultural commodities, such as papaya, avocado, banana, tomato, bell pepper, grapefruit, guava, and loquat. The fumigation of "Sunrise" papaya with 0.01 or $0.1 \mathrm{mM}$ MeJA vapors for $16 \mathrm{~h}$ significantly suppressed CI symptoms, such as fungal decay, surface pitting, and loss of firmness, after $32 \mathrm{~d}$ storage at $10^{\circ} \mathrm{C}+4 \mathrm{~d}$ shelf life at $20^{\circ} \mathrm{C}$ [43].

Based on the report of Aghdam and Bodbodak [75], the JAs-mediated chilling alleviation of postharvest horticultural commodities could be due to the physiological and biochemical responses as follows: (1) enhancement of membrane integrity through the increase of unsaturated fatty acids/saturated fatty acids (unSFA/SFA) ratio; (2) enhancement of heat shock proteins (HSPs) gene expression; (3) enhancement of reactive oxygen intermediates- (ROIs-) scavenging capacity; (4) enhancement of arginine pathways, resulting in the accumulation of bioactive molecules with pivotal roles in chilling resistance; (5) enhancement of energy metabolism, leading to more adenosine triphosphate (ATP) accumulation; (6) alteration in phenylalanine ammonia-lyase (PAL) and polyphenol oxidase (PPO) activities (Table 2).

Cultivar, ripening stage, and JAs dosage can impact the efficiency of JAs treatment [20, 25]. Ding et al. [16] found that a $0.1 \mathrm{mM}$ MeJA fumigation of breaker "Beefsteak" tomato prior to $28 \mathrm{~d}$ storage at $5^{\circ} \mathrm{C}$ substantially inhibited the development of surface pitting and Alternaria decay; however, this concentration was not effective for pink fruit [76]. Although $0.037,0.074$, or $0.110 \mathrm{mM}$ MeJA fumigation could effectively suppress pitting, browning, and water loss during low temperature storage of "Malas Save" pomegranate fruits, the optimal result was observed in fruits treated with the highest concentration [49].

\section{Roles of CBF-Dependent Signaling Pathway during Low Temperature Stress}

5.1. Activation of CBF-Dependent Signaling Pathway during Low Temperature Stress. Upon exposure to low temperature, plants immediately activate multiple signaling pathways to enhance chilling tolerance, which consists of transcriptional, posttranscriptional, translational, and posttranslational regulators of low temperature-induced expression of the functional genes [6]. In the promoters of these genes, there is a kind of cis-elements termed C-repeat elements/dehydrationresponsive elements (CRT/DRE), where CBFs can bind [7]. CBFs, which participate in transcriptional regulation of low temperature acclimation [6], are under the positive 


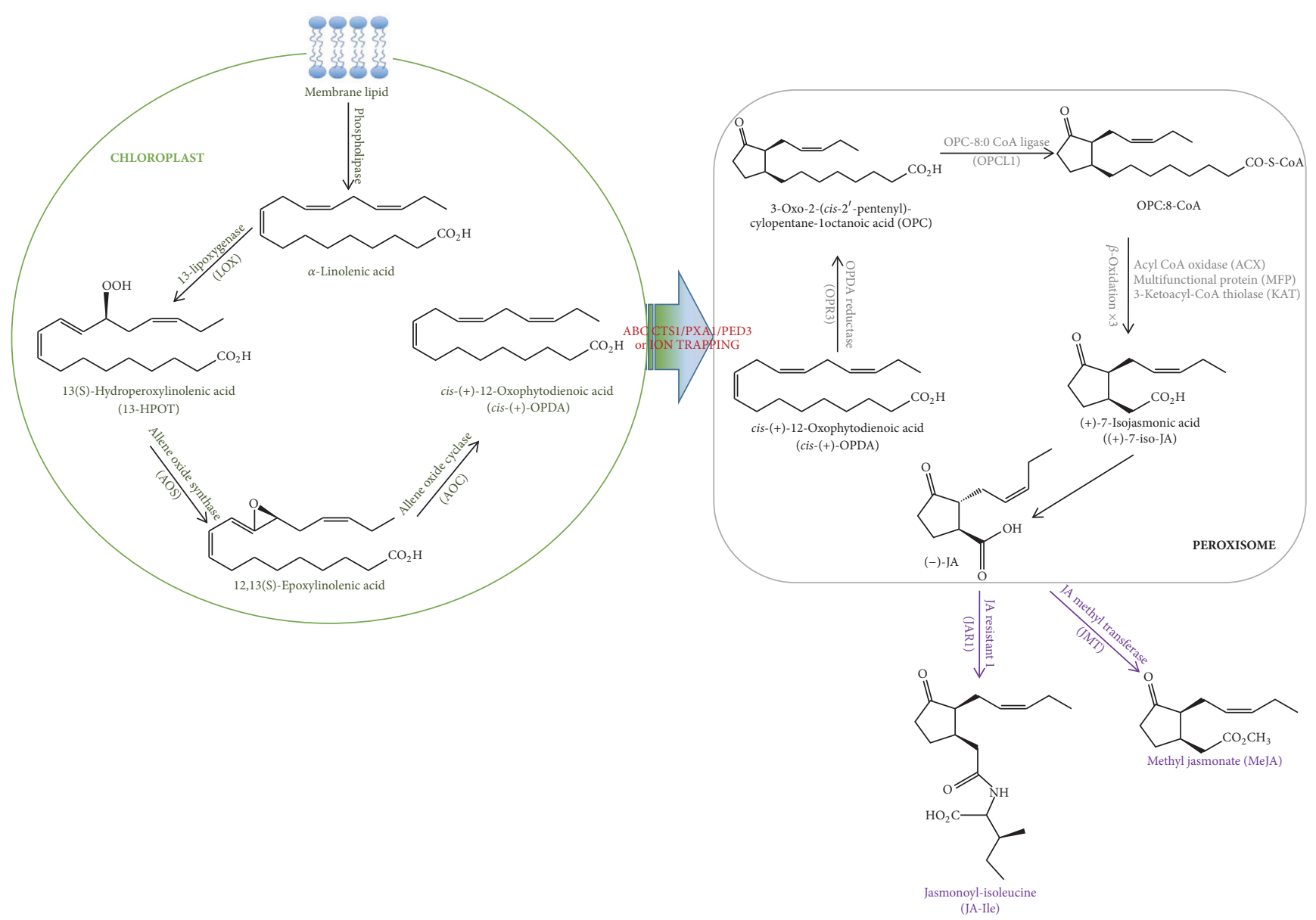

Figure 2: Biosynthetic pathway of jasmonates (JAs) [58, 71, 72].

control of the upstream ICEs, including ICE1 and ICE2 [8]. Activation of CBF-dependent signaling pathway, especially the ICE1-CBF transcriptional cascade, is supposed to be a key responder to low temperature stress in plant, enhancing their chilling resistance $[6,9]$. Chilling stress results in the induction of OsICE1 and OsICE2 in rice (Oryza sativa) and subsequent upregulation of $O s C B F 1$, rice heat shock factor A3 (OsHsfA3), and rice trehalose 6-phosphate phosphatase 1 (OsTPP1) expression [80]. Overexpression of SlICE1 in tomato fruit initiates the expression of SlCBF1, dehydrin Ci7 homolog (SlDRCi7), and pyrroline-5-carboxylate synthetase (SlP5CS) and enhance the accumulation of antioxidants, several amino acids, amines, and sugars, thus improving the chilling resistance of fruit $[81,82]$. A similar result was observed in cucumber [83].

In Arabidopsis, three CBFs-namely, AtCBF1, AtCBF2, and AtCBF3 - have been identified to be involved in low temperature stress [10]. Under normal condition, JAZ1 and JAZ4 in Arabidopsis would interact with ICEs, thus suppressing CBF-dependent signaling pathway [84]. Upon low temperature acclimation when the biosynthesis of endogenous JAs is induced, ICE1 is released from the JAZs via a $26 \mathrm{~S}$ proteasome-mediated degradation and then positively regulates the expression of CBFs [78]. Subsequently, CBFs bind to CRT/DRE in CORs and upregulate their expression, which could induce the physiological and biochemical responses and thus improve chilling tolerance of plant [6]. For the detailed information on the roles of CBF-dependent signaling pathway in chilling acclimation, readers could refer to the reviews on this topic $[6,85,86]$.

\subsection{Physiological and Biochemical Responses Induced by CBF-Dependent Signaling Pathway to Improve Chilling Tolerance}

5.2.1. Enhancing Arginine Pathways. Arginine is a precursor for the biosynthesis of bioactive molecules such as polyamines, proline, and $\gamma$-aminobutyric acid $[36,52]$ (Figure 4). Polyamines could stabilize the membrane based on its polycationic nature at physiological $\mathrm{pH}$ [87], proline acts as a protein-compatible hydrotrope or as a hydroxyl radical scavenger to regulate the $\mathrm{NAD}+/ \mathrm{NADH}$ ratio [88], while $\gamma$-aminobutyric acid is involved in osmotic regulation, ROS scavenge, and intracellular signal transduction [89].

As shown in Figure 4, in plant arginase is metabolised by arginase (ARG), ornithine decarboxylase (ODC), and arginine decarboxylase (ADC) with ornithine and agmatine as intermetabolites [52]. Ornithine could also be converted into $\gamma$-aminobutyric acid by P5CS and glutamate decarboxylase 

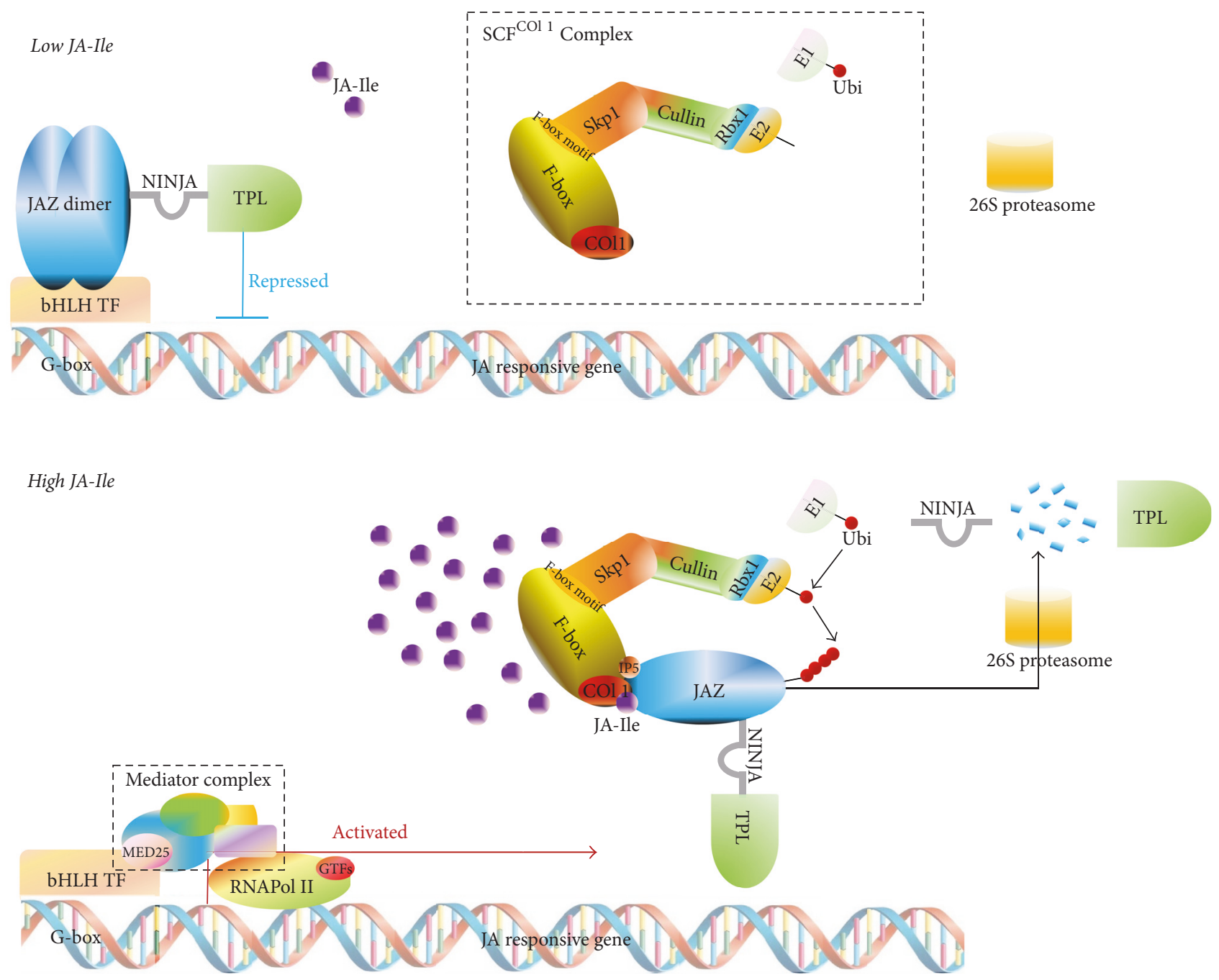

FIGURE 3: Signal transduction of jasmonates (JAs) [58, 71].

(GAD) or into proline by pyrroline-5-carboxylate reductase (P5CR) (Figure 4) [36, 52].

CBF-dependent signaling pathway plays a pivotal role in arginine metabolism. Tomato with upregulated expression of SlICE1 showed higher expression levels of SIP5CS and higher concentrations of polyamines, proline, and $\gamma$-aminobutyric acid, thus improving the chilling tolerance of fruit [81, 82]. A similar phenomenon was observed by the overexpression of AtCBF3/DREB1A in Arabidopsis [24].

5.2.2. Enhancing ROIs-Scavenging Capacity. ROIs are the partially reduced forms of $\mathrm{O}_{2}$ [90]. Chilling exposure could stimulate the production and overaccumulation of ROIs, which disrupts the cellular homeostasis and cause cell death [77, 91]. In plant, the major ROIs-scavenging pathways consist of (i) water-water cycle; (ii) ascorbate-glutathione cycle; (iii) glutathione-peroxidase (GPX) cycle; and (iv) catalase (CAT) [77] (Figure 5). Among these, the ascorbateglutathione cycle plays a crucial role in regulating ROIs based on its wide distribution as well as the high affinity of ascorbate peroxidase (APX) for $\mathrm{H}_{2} \mathrm{O}$.
ROIs-scavenging capacity in plant is correlated with CBFdependent signaling pathway. Overexpression of SIICE1 in tomatoes could enhance the accumulation of antioxidants, such as $\beta$-carotene, lycopene, and ascorbic acid, as well as antioxidant activity, thus improving the chilling tolerance of tomato $[81,82]$.

5.2.3. Enhancing Energy Metabolism. Energy supply is also very important during the stress response as an ATP deficit would induce membrane lipid peroxidation and subsequently generate more free radicals, which would attack the cellular membrane $[92,93]$. In plant, ATP is synthesized from glucose by a series of pathways, including glycolysis, Kreb's cycle, electron transfer chain, and oxidative phosphorylation.

CBF-dependent signaling pathway is supposed to be involved in energy metabolism. Overexpression of SIICE1 in tomato enhanced the accumulation of metabolites relevant to ATP generation, such as glucose, fructose, glucose 6phosphate, fructose 1,6-diphosphate, phosphoenolpyruvate, citric acid, and succinic acid, thus improving the chilling tolerance of tomato $[81,82]$. Similarly, overexpression of the 


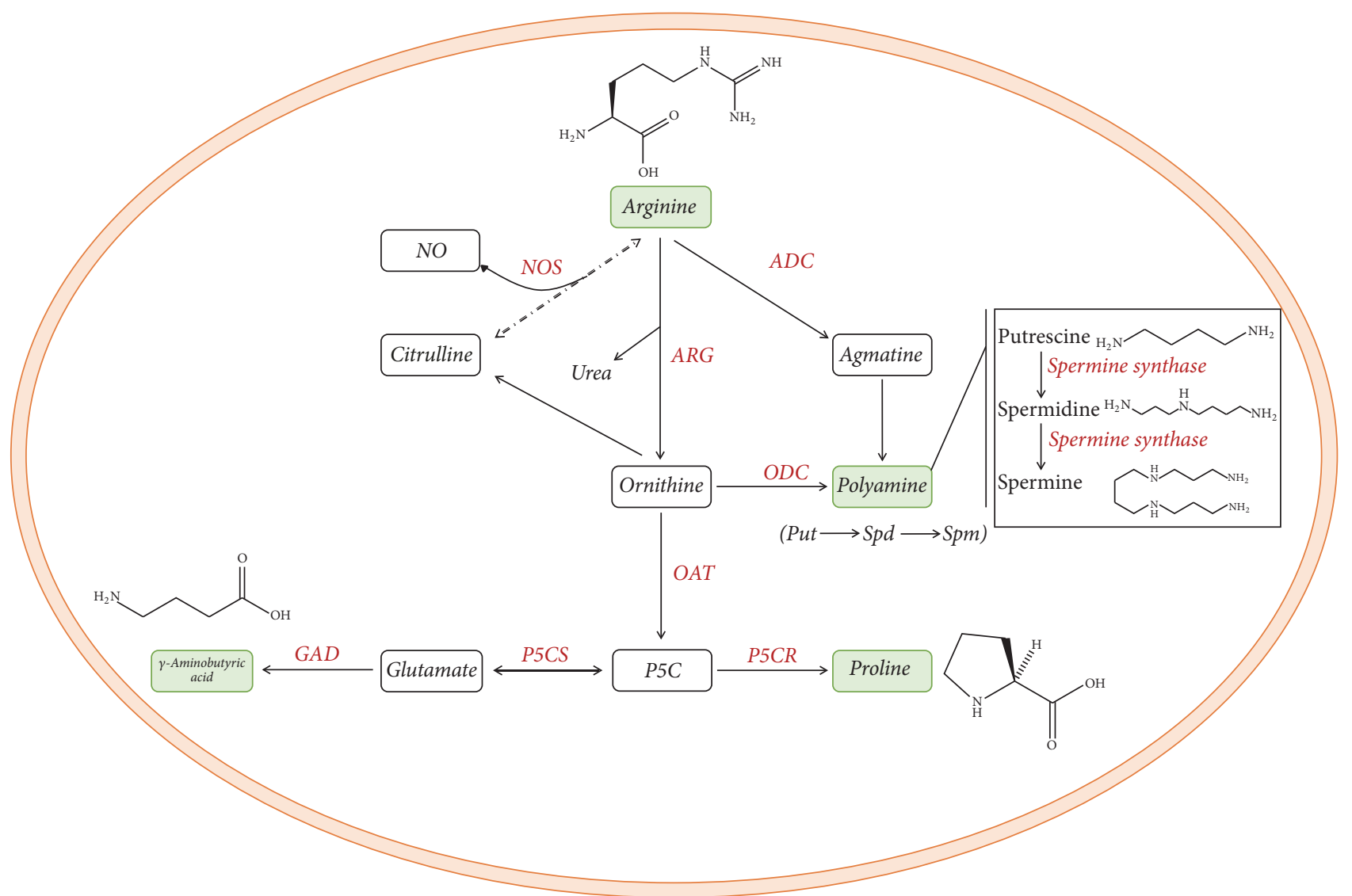

Figure 4: Arginine pathways which lead to the production of polyamines, proline, and $\gamma$-aminobutyric acid [52, 75]. Enzyme abbreviations are as follows: ADC, arginine decarboxylase; ARG, arginase; GAD, glutamate decarboxylase; NOS, NO synthase; ODC, ornithine decarboxylase; P5CR, pyrroline-5-carboxylate reductase; P5CS, pyrroline-5-carboxylate synthetase.

AtCBF3 could enhance the chilling tolerance of Arabidopsis, which was associated with higher abundances of glucose and fructose [24].

5.2.4. Enhancing the Expression of HSPs. HSPs, a stressresponsive family of proteins with molecular weight between 15 and $115 \mathrm{kDa}$, are comprised of five subfamilies, including HSP70s, HSP60s, HSP90s, HSP100s, and small HSPs (sHSPs) [5]. They are widely distributed within cellular compartments and exert their protective role against stress based on molecular chaperone activity to sustain protein trafficking as well as maintain the integrity and function of the cell membrane $[7,94]$. Furthermore, sHSPs can exert molecular chaperone activity independent of ATP [95].

The expression levels of HSPs genes are regulated by the CBF-dependent signaling pathway $[96,97]$. Previously, Nakamura et al. [80] found that chilling stress caused the induction of OsICE1 and OsICE2 in rice and subsequent upregulation of $O s C B F 1, O s H s f A 3$, and OsTPP1 expression.

\section{Linkage between JAs Signal Transduction and CBF-Dependent Signaling Pathway}

Although several physiological and biochemical responses are observed after JAs treatment, the mechanism has not been clarified until recently. Activation of the CBF-dependent signaling pathway, especially the ICE1-CBF transcriptional cascade, is proposed to perform a large duty during JAs-induced chilling tolerance. Previously, Zhao et al. [9] observed that MYC2 was involved in JAs-induced chilling tolerance through physical interaction and functional coordination with ICE1, regulating the CBF-dependent signaling pathway. In association with the higher expression of MaMYC2a and $M a M Y C 2 b$ after dipping "Carvendish" banana in $0.1 \mathrm{mM}$ MeJA solution for $30 \mathrm{~min}$ was the enhanced expression of $M a C B F 1, M a C B F 2$, and CBF downstream genes, including COR1, KIN2, RD2, and RD5 [9]. Since MYC2 is one of the TFs in JAs signal transduction pathway, these results imply a potential linkage between two signal transduction pathways. Furthermore, various physiological and biochemical responses induced by CBF-dependent signaling pathway were also observed in postharvest horticultural commodities after JAs treatment (see Sections 4 and 5).

In combination with previous reports $[6,9,78,84]$, the primary signal transduction process after prechilling JAs treatment to activate CBF-dependent signaling pathway in order to improve the chilling resistance of postharvest horticultural commodities is illustrated in Figure 6: higher JAs content after prechilling JAs treatment triggers COI1mediated degradation of JAZs, releasing MYC2 and ICE1 


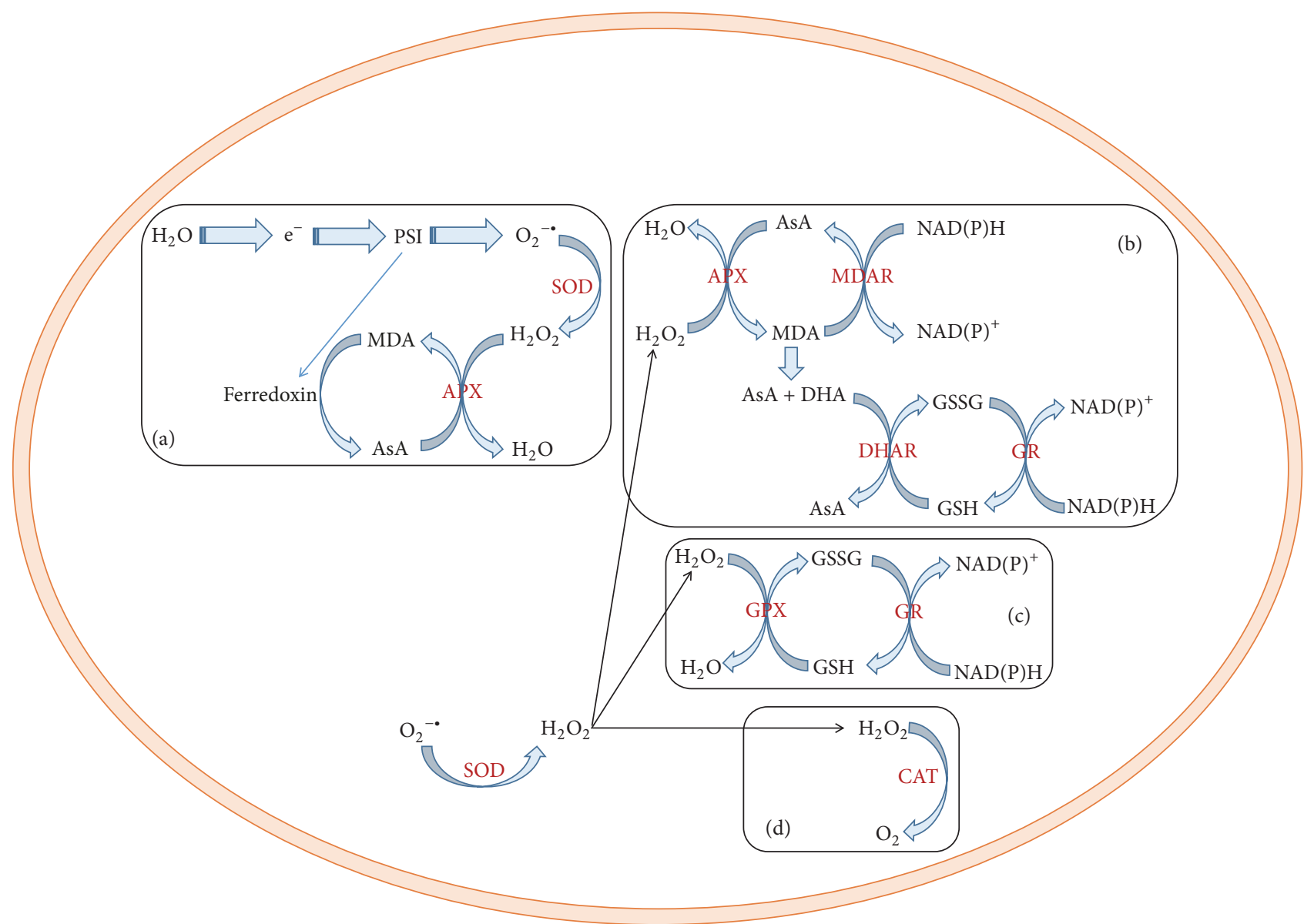

FIGURE 5: Reactive oxygen intermediates- (ROIs-) scavenging pathways in plant [77]. (a) Water-water cycle, (b) ascorbate-glutathione cycle, (c) glutathione-peroxidase (GPX) cycle, and (d) catalase (CAT). Enzyme abbreviations are as follows: APX, ascorbate peroxidase; AsA, ascorbic acid; SOD, superoxide dismutase; DHA, dehydroascorbate; DHAR, dehydroascorbate reductase; GR, glutathione reductase; GSH, glutathione; GSSG, oxidized glutathione; $\mathrm{H}_{2} \mathrm{O}_{2}$, hydrogen peroxide; MDA, monodehydroascorbate; MDAR, monodehydroascorbate reductase; PSI, photosystem I.

from repression. MYC2 and ICE1 then interact with each other to activate the expression of CBFs, which subsequently bind to the CRT/DRE box promoter sequence element to induce the expression of CBF downstream genes, such as CORs [79]. The induction of CORs expression needs SENSITIVE TO FREEZING 6 (SFR6) to recruit RNA polymerase II to the promoter [98]. Following this is the initiation of the gene expression downstream, which subsequently induces various physiological and biochemical responses, resulting in the improvement in the chilling tolerance of postharvest horticultural commodities.

\section{Conclusions and Perspectives}

Activation of CBF-dependent signaling pathway, especially the ICE1-CBF transcriptional cascade, is proposed to be a key response to low temperature stress in plant, enhancing their chilling tolerance $[6,9]$.

Prechilling JAs treatment shows a potential to alleviate the CI of postharvest horticultural commodities. However, our understanding of its mechanism is still rudimentary. In association with new discoveries in JAs biosynthesis, signal transduction, and the roles of the CBF-dependent signaling pathway during chilling stress, the linkage between JAs signal transduction and CBF-dependent signaling pathway is identified. This review summarizes the previous studies relevant to JAs and CBF-dependent signaling pathway and further proposed the primary signal transduction process after JAs treatment to activate CBF-dependent signaling pathway to enhance the chilling tolerance (Figure 6). However, there are still some questions which need to be addressed, such as the roles of other MYCs (except for MYC2) in the activation of CBF-dependent signaling pathway.

In addition, according to microarray and real-time analysis of wild-type Arabidopsis and its coil mutant, $\mathrm{Hu}$ et al. [84] observed that transcriptional levels of some CORs, which were not induced by CBF-dependent signaling pathway, were lower in coil mutant upon low temperature exposure. These results suggest that some physiological and biochemical responses might result from CBF-independent signaling pathway [84]. Thus, further work is needed to clarify the roles of the physiological and biochemical responses induced by 


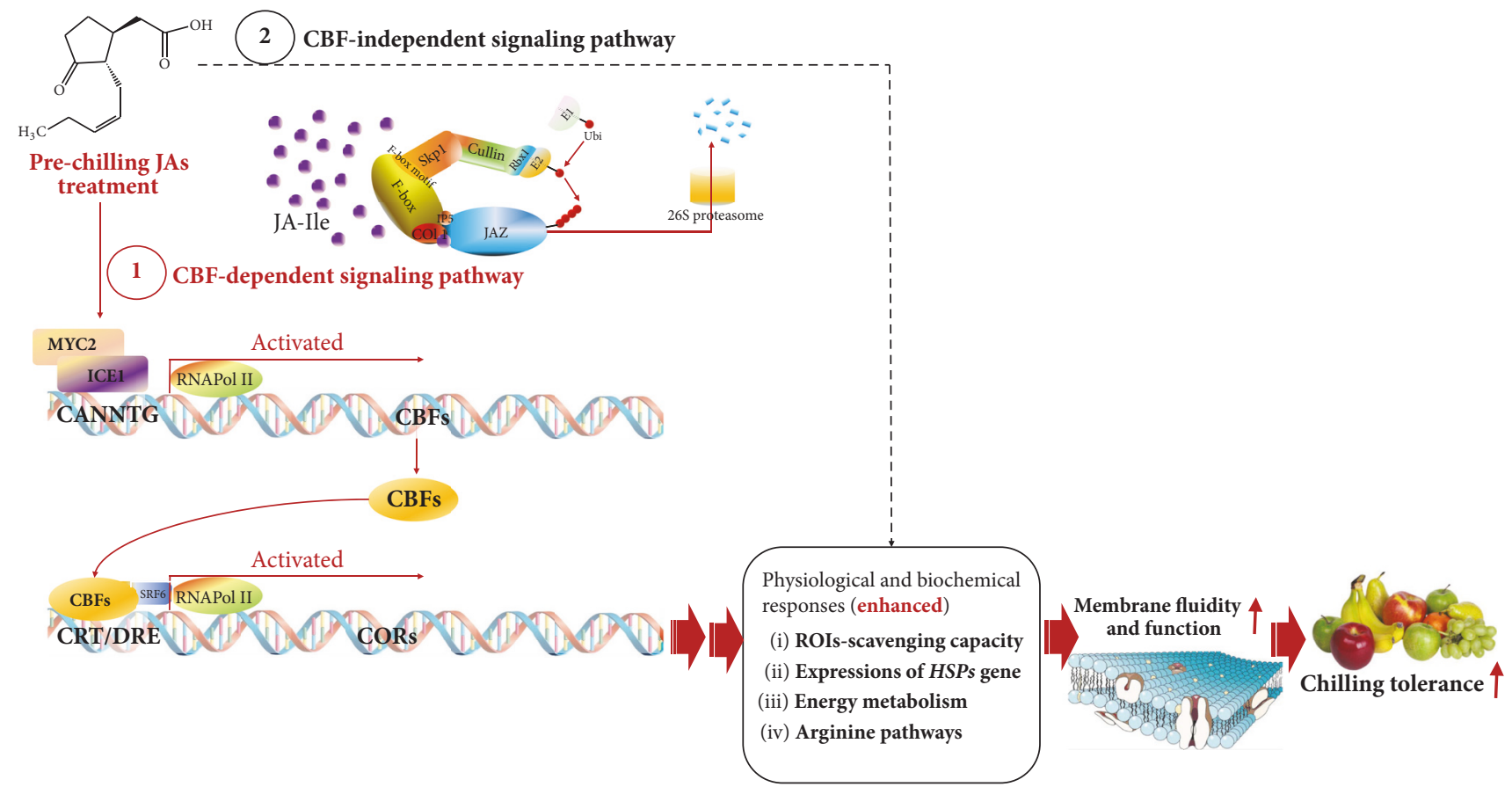

FIGURE 6: Prechilling jasmonates (JAs) treatment activates CBF-dependent signaling pathway and thus induce physiological and biochemical responses to enhance the chilling tolerance of postharvest horticultural commodities $[9,78,79]$.

the CBF-independent signal pathway and their roles in JAsmediated chilling resistance with the aid of genomics, proteomics, transcriptomics, and metabolomics, which will give us a more comprehensive understanding on the mechanism employed by exogenous JAs application to mitigate CI symptoms of postharvest horticultural commodities.

\section{Conflicts of Interest}

The authors have declared that no conflicts of interest exist regarding the publication of this paper.

\section{Authors' Contributions}

Libin Wang wrote the paper; Weiqi Luo, Xiuxiu Sun, and Chunlu Qian searched and collected the material.

\section{Acknowledgments}

The authors would like to thank the National Natural Science Foundation of China (31701868), the Fundamental Research Funds for the Central Universities (Y0201700670), Public Welfare Research Projects of the Ministry of Agriculture of China (2014030232), and Metabolomic \& Microbial Profiling of Tropical/Subtropical Fruits and Small Fruits for Quality Factors and Microbial Stability (6034-41430-005-00) for the financial support of this study. Meanwhile, they thank Dr. Christopher Ference (Horticultural Research Laboratory, Fort Pierce, Florida, USA) for English language editing and Shaoling Zhang for providing some advice for manuscript construction and some financial support.

\section{References}

[1] R. E. Hardenburg, A. E. Watada, and C. Yang, "The commercial storage of fruits, vegetables, and florist and nursery stocks," Agriculture Handbook, vol. 66, 1990.

[2] L. Sevillano, M. T. Sanchez-Ballest, F. Romojaro, and F. B. Flores, "Physiological, hormonal and molecular mechanisms regulating chilling injury in horticultural species. Postharvest technologies applied to reduce its impact," Journal of the Science of Food and Agriculture, vol. 89, no. 4, pp. 555-573, 2009.

[3] C. Y. Wang, "Chilling injury of fruits and vegetables," Food Reviews International, vol. 5, no. 2, pp. 209-236, 1989.

[4] R. E. Paull, "Chilling injury of crops of tropical and subtropical origin," in Chilling Injury of Horticultural Crops, pp. 17-36, CRC Press, 1990.

[5] M. S. Aghdam and S. Bodbodak, "Postharvest Heat Treatment for Mitigation of Chilling Injury in Fruits and Vegetables," Food and Bioprocess Technology, vol. 7, no. 1, pp. 37-53, 2014.

[6] M. Q. Zhou, C. Shen, L. H. Wu, K. X. Tang, and J. Lin, "CBF-dependent signaling pathway: A key responder to low temperature stress in plants," Critical Reviews in Biotechnology, vol. 31, no. 2, pp. 186-192, 2011.

[7] M. F. Thomashow, "Plant cold acclimation: Freezing tolerance genes and regulatory mechanisms," Annual Review of Plant Biology, vol. 50, pp. 571-599, 1999.

[8] O. V. Fursova, G. V. Pogorelko, and V. A. Tarasov, "Identification of ICE2, a gene involved in cold acclimation which determines freezing tolerance in Arabidopsis thaliana," Gene, vol. 429, no. 1-2, pp. 98-103, 2009.

[9] M.-L. Zhao, J.-N. Wang, W. Shan et al., "Induction of jasmonate signalling regulators MaMYC2s and their physical interactions with MaICE1 in methyl jasmonate-induced chilling tolerance in banana fruit," Plant, Cell \& Environment, vol. 36, no. 1, pp. 30-51, 2013. 
[10] K. Miura and T. Furumoto, "Cold signaling and cold response in plants," International Journal of Molecular Sciences, vol. 14, no. 3, pp. 5312-5337, 2013.

[11] J. T. Vogel, D. G. Zarka, H. A. Van Buskirk, S. G. Fowler, and M. F. Thomashow, "Roles of the CBF2 and ZAT12 transcription factors in configuring the low temperature transcriptome of Arabidopsis," The Plant Journal, vol. 41, no. 2, pp. 195-211, 2005.

[12] S. Fonseca, J. M. Chico, and R. Solano, "The jasmonate pathway: the ligand, the receptor and the core signalling module," Current Opinion in Plant Biology, vol. 12, no. 5, pp. 539-547, 2009.

[13] P. Vijayan, J. Shockey, C. A. Lévesque, R. J. Cook, and J. Browse, "A role for jasmonate in pathogen defense of Arabidopsis," Proceedings of the National Acadamy of Sciences of the United States of America, vol. 95, no. 12, pp. 7209-7214, 1998.

[14] N. Bodenhausen and P. Reymond, "Signaling pathways controlling induced resistance to insect herbivores in Arabidopsis," Molecular Plant-Microbe Interactions, vol. 20, no. 11, pp. 14061420, 2007.

[15] R. A. Creelman, M. L. Tierney, and J. E. Mullet, "Jasmonic acid/ methyl jasmonate accumulate in wounded soybean hypocotyls and modulate wound gene expression," Proceedings of the National Acadamy of Sciences of the United States of America, vol. 89, no. 11, pp. 4938-4941, 1992.

[16] C.-K. Ding, C. Y. Wang, K. C. Gross, and D. L. Smith, "Jasmonate and salicylate induce the expression of pathogenesisrelated-protein genes and increase resistance to chilling injury in tomato fruit," Planta, vol. 214, no. 6, pp. 895-901, 2002.

[17] H. Pedranzani, G. Racagni, S. Alemano et al., "Salt tolerant tomato plants show increased levels of jasmonic acid," Plant Growth Regulation, vol. 41, no. 2, pp. 149-158, 2003.

[18] C. Wasternack and B. Hause, "Jasmonates and octadecanoids: signals in plant stress responses and development," Progress in Nucleic Acid Research and Molecular Biology, vol. 72, pp. 165221, 2002.

[19] C. Wasternack and B. Hause, "Jasmonates: Biosynthesis, perception, signal transduction and action in plant stress response, growth and development. An update to the 2007 review in Annals of Botany," Annals of Botany, vol. 111, no. 6, pp. 10211058, 2013.

[20] C. Y. Wang, "Alleviation of chilling injury in tropical and subtropical fruits," Acta Horticulturae, vol. 864, pp. 267-274, 2010.

[21] W. Autio and W. Bramlage, "Chilling sensitivity of tomato fruit in relation to ripening and senescence," Journal of the American Society for Horticultural Science, vol. 111, no. 2, pp. 201-204, 1986.

[22] F. Maul, S. A. Sargent, C. A. Sims, E. A. Baldwin, M. O. Balaban, and D. J. Huber, "Tomato flavor and aroma quality as affected by storage temperature," Journal of Food Science, vol. 65, no. 7, pp. 1228-1237, 2000.

[23] B. D. Patterson and M. S. Reid, "Genetic and environmental influences on the expression of chilling injury," in Chilling Injury of Horticultural Crops, pp. 87-112, CRC Press, 1990.

[24] S. J. Gilmour, A. M. Sebolt, M. P. Salazar, J. D. Everard, and M. F. Thomashow, "Overexpression of the arabidopsis CBF3 transcriptional activator mimics multiple biochemical changes associated with cold acclimation," Plant Physiology, vol. 124, no. 4, pp. 1854-1865, 2000.

[25] S. Meir, S. Philosoph-Hadas, S. Lurie et al., "Reduction of chilling injury in stored avocado, grapefruit, and bell pepper by methyl jasmonate," Botany, vol. 74, no. 6, pp. 870-874, 1996.
[26] P. Chaiprasart, H. Gemma, and S. Iwahori, "Reduction of chilling injury in stored banana fruits by jasmonic acid derivative and abscisic acid treatment," Acta Horticulturae, vol. 575, pp. 689-696, 2002.

[27] N. Pongprasert, S. Kanlayanarat, H. Gemma, Y. Sekozawa, and S. Sugaya, "Postharvest n-propyl dihydrojasmonate and abscisic acid application on reducing chilling injury in banana peel," Acta Horticulturae, vol. 712, pp. 741-746, 2006.

[28] S. Kondo, M. Kittikorn, and S. Kanlayanarat, "Preharvest antioxidant activities of tropical fruit and the effect of low temperature storage on antioxidants and jasmonates," Postharvest Biology and Technology, vol. 36, no. 3, pp. 309-318, 2005.

[29] R. W. M. Fung, C. Y. Wang, D. L. Smith, K. C. Gross, and M. Tian, "MeSA and MeJA increase steady-state transcript levels of alternative oxidase and resistance against chilling injury in sweet peppers (Capsicum annuum L.)," Journal of Plant Sciences, vol. 166, no. 3, pp. 711-719, 2004.

[30] S. Droby, R. Porat, L. Cohen et al., "Suppressing green mold decay in grapefruit with postharvest jasmonate application," Journal of the American Society for Horticultural Science, vol. 124, no. 2, pp. 184-188, 1999.

[31] G. A. González-Aguilar, M. E. Tiznado-Hernández, R. ZavaletaGatica, and M. A. Martínez-Téllez, "Methyl jasmonate treatments reduce chilling injury and activate the defense response of guava fruits," Biochemical and Biophysical Research Communications, vol. 313, no. 3, pp. 694-701, 2004.

[32] S. Cao, Y. Zheng, K. Wang, P. Jin, and H. Rui, "Methyl jasmonate reduces chilling injury and enhances antioxidant enzyme activity in postharvest loquat fruit," Food Chemistry, vol. 115, no. 4, pp. 1458-1463, 2009.

[33] S. Cao, Y. Zheng, K. Wang, H. Rui, and S. Tang, "Effect of methyl jasmonate on cell wall modification of loquat fruit in relation to chilling injury after harvest," Food Chemistry, vol. 118, no. 3, pp. 641-647, 2010.

[34] S. F. Cao, X. Q. Wang, Z. F. Yang et al., "Effects of methyl jasmonate treatment on quality and decay in cold-stored loquat fruit," Acta Horticulturae, vol. 750, pp. 425-430, 2007.

[35] Y. Cai, S. Cao, Z. Yang, and Y. Zheng, "MeJA regulates enzymes involved in ascorbic acid and glutathione metabolism and improves chilling tolerance in loquat fruit," Postharvest Biology and Technology, vol. 59, no. 3, pp. 324-326, 2011.

[36] S. Cao, Y. Cai, Z. Yang, and Y. Zheng, "MeJA induces chilling tolerance in loquat fruit by regulating proline and $\gamma$-aminobutyric acid contents," Food Chemistry, vol. 133, no. 4, pp. 1466-1470, 2012.

[37] G. A. González-Aguilar, J. G. Buta, and C. Y. Wang, "Methyl jasmonate reduces chilling injury symptoms and enhances colour development of 'Kent' mangoes," Journal of the Science of Food and Agriculture, vol. 81, no. 13, pp. 1244-1249, 2001.

[38] A. Tasneem, Postharvest treatments to reduce chilling injury symptoms in stored mangoes [Master, thesis], Master Thesis. Macdonald Campus of McGill University, Montreal, Canada, 2004.

[39] C. Junmatong, J. Uthaibutra, D. Boonyakiat, B. Faiyue, and K. Saengnil, "Reduction of Chilling Injury of 'Nam Dok Mai No. 4' Mango Fruit by Treatments with Salicylic Acid and Methyl Jasmonate," Journal of Agricultural Science, vol. 4, no. 10, 2012.

[40] G. A. González-Aguilar, J. Fortiz, R. Cruz, R. Baez, and C. Y. Wang, "Methyl jasmonate reduces chilling injury and maintains postharvest quality of mango fruit," Journal of Agricultural and Food Chemistry, vol. 48, no. 2, pp. 515-519, 2000. 
[41] S. Kondo, A. Jitratham, M. Kittikorn, and S. Kanlayanarat, "Relationships between jasmonates and chilling injury in mangosteens are affected by spermine," HortScience, vol. 39, no. 6, pp. 1346-1348, 2004.

[42] N. Boontongto, V. Srilaong, A. Uthairatanakij, C. Wongs-Aree, and K. Aryusuk, "Effect of methyl jasmonate on chilling injury of okra pod," Acta Horticulturae, vol. 746, pp. 323-327, 2007.

[43] G. A. González-Aguilar, J. G. Buta, and C. Y. Wang, "Methyl jasmonate and modified atmosphere packaging (MAP) reduce decay and maintain postharvest quality of papaya "Sunrise", Postharvest Biology and Technology, vol. 28, no. 3, pp. 361-370, 2003.

[44] P. Jin, K. Wang, H. Shang, J. Tong, and Y. Zheng, "Lowtemperature conditioning combined with methyl jasmonate treatment reduces chilling injury of peach fruit," Journal of the Science of Food and Agriculture, vol. 89, no. 10, pp. 1690-1696, 2009.

[45] P. Jin, Y. Zheng, S. Tang, H. Rui, and C. Y. Wang, "A combination of hot air and methyl jasmonate vapor treatment alleviates chilling injury of peach fruit," Postharvest Biology and Technology, vol. 52, no. 1, pp. 24-29, 2009.

[46] P. Jin, H. Zhu, J. Wang, J. Chen, X. Wang, and Y. Zheng, "Effect of methyl jasmonate on energy metabolism in peach fruit during chilling stress," Journal of the Science of Food and Agriculture, vol. 93, no. 8, pp. 1827-1832, 2013.

[47] X. Meng, J. Han, Q. Wang, and S. Tian, "Changes in physiology and quality of peach fruits treated by methyl jasmonate under low temperature stress," Food Chemistry, vol. 114, no. 2-3, pp. 1028-1035, 2009.

[48] P. Nilprapruck, N. Pradisthakarn, F. Authanithee, and et al., "Effect of exogenous methyl jasmonate on chilling injury and quality of pineapple (Ananas comosus L.) cv. Pattavia," Silpakorn University Science and Technology Journal, vol. 2, no. 2, pp. 33-42, 2008.

[49] R. Zolfagharinasab and J. Hadian, "Influence of methyl jasmonate on inducing chilling tolerance in pomegranate fruits (Malas Save)," Pakistan Journal of Biological Sciences, vol. 10, no. 4, pp. 612-616, 2007.

[50] M. Sayyari, M. Babalar, S. Kalantari et al., "Vapour treatments with methyl salicylate or methyl jasmonate alleviated chilling injury and enhanced antioxidant potential during postharvest storage of pomegranates," Food Chemistry, vol. 124, no. 3, pp. 964-970, 2011.

[51] C.-K. Ding, C. Y. Wang, K. C. Gross, and D. L. Smith, "Reduction of chilling injury and transcript accumulation of heat shock proteins in tomato fruit by methyl jasmonate and methyl salicylate," Journal of Plant Sciences, vol. 161, no. 6, pp. 1153-1159, 2001.

[52] X. Zhang, J. Sheng, F. Li, D. Meng, and L. Shen, "Methyl jasmonate alters arginine catabolism and improves postharvest chilling tolerance in cherry tomato fruit," Postharvest Biology and Technology, vol. 64, no. 1, pp. 160-167, 2012.

[53] C. Y. Wang and J. G. Buta, "Methyl jasmonate reduces chilling injury in Cucurbita pepo through its regulation of abscisic acid and polyamine levels," Environmental and Experimental Botany, vol. 34, no. 4, pp. 427-432, 1994.

[54] Y. Chien, "Methyl jasmonate improves quality of stored zucchini squash," Journal of Food Quality, vol. 22, no. 6, pp. 663670, 1999.

[55] J. M. Lyons, "Chilling Injury in Plants," Annual Review of Plant Biology, vol. 24, no. 1, pp. 445-466, 1973.
[56] J. K. Raison, J. M. Lyons, R. J. Mehlhorn, and A. D. Keith, "Temperature-induced phase changes in mitochondrial membranes detected by spin labeling.," The Journal of Biological Chemistry, vol. 246, no. 12, pp. 4036-4040, 1971.

[57] G. Bannenberg, M. Martínez, M. Hamberg, and C. Castresana, "Diversity of the enzymatic activity in the lipoxygenase gene family of arabidopsis thaliana," Lipids, vol. 44, no. 2, pp. 85-95, 2009.

[58] A. Santino, M. Taurino, S. De Domenico et al., "Jasmonate signaling in plant development and defense response to multiple (a)biotic stresses," Plant Cell Reports, vol. 32, no. 7, pp. 10851098, 2013.

[59] Y. Pi, K. Jiang, Y. Cao et al., "Allene oxide cyclase from camptotheca acuminata improves tolerance against low temperature and salt stress in tobacco and bacteria," Molecular Biotechnology, vol. 41, no. 2, pp. 115-122, 2009.

[60] A. J. Koo and G. A. Howe, "Role of peroxisomal $\beta$-oxidation in the production of plant signaling compounds," Plant Signaling \& Behavior, vol. 2, no. 1, pp. 20-22, 2007.

[61] C. Meesters and E. Kombrink, "Jasmonic Acid," in Plant Chemical Biology, pp. 160-183, John Wiley \& Sons Inc, 2014.

[62] C. Wasternack, "Jasmonates: An update on biosynthesis, signal transduction and action in plant stress response, growth and development," Annals of Botany, vol. 100, no. 4, pp. 681-697, 2007.

[63] H. Weber, B. A. Vick, and E. E. Farmer, "Dinor-oxophytodienoic acid: A new hexadecanoid signal in the jasmonate family," Proceedings of the National Acadamy of Sciences of the United States of America, vol. 94, no. 19, pp. 10473-10478, 1997.

[64] A. Scala, S. Allmann, R. Mirabella, M. A. Haring, and R. C. Schuurink, "Green leaf volatiles: A plant's multifunctional weapon against herbivores and pathogens," International Journal of Molecular Sciences, vol. 14, no. 9, pp. 17781-17811, 2013.

[65] J. Bai, E. A. Baldwin, Y. Imahori, I. Kostenyuk, J. Burns, and J. K. Brecht, "Chilling and heating may regulate C6 volatile aroma production by different mechanisms in tomato (Solanum lycopersicum) fruit," Postharvest Biology and Technology, vol. 60, no. 2, pp. 111-120, 2011.

[66] X. Tong, J. Qi, X. Zhu et al., "The rice hydroperoxide lyase OsHPL3 functions in defense responses by modulating the oxylipin pathway," The Plant Journal, vol. 71, no. 5, pp. 763-775, 2012.

[67] J. M. Chico, A. Chini, S. Fonseca, and R. Solano, "JAZ repressors set the rhythm in jasmonate signaling," Current Opinion in Plant Biology, vol. 11, no. 5, pp. 486-494, 2008.

[68] B. Thines, L. Katsir, M. Melotto et al., "JAZ repressor proteins are targets of the SCFCOI1 complex during jasmonate signalling," Nature, vol. 448, no. 7154, pp. 661-665, 2007.

[69] L. B. Sheard, X. Tan, H. Mao et al., "Jasmonate perception by inositol-phosphate-potentiated COI1-JAZ co-receptor," Nature, vol. 468, no. 7322, pp. 400-407, 2010.

[70] A. Kacperska, "Plant responses to low temperature: signaling pathways involved in plant acclimation," in Cold-adapted Organisms Ecology, Physiology, Enzymology and Molecular Biology, pp. 79-103, Springer-Verlag, 1999.

[71] S. Gimenez-Ibanez, M. Boter, and R. Solano, "Novel players fine-tune plant trade-offs," Essays in Biochemistry, vol. 58, pp. 83-100, 2015.

[72] Y. Yan, E. Borrego, and M. V. Kolomiets, "Jasmonate biosynthesis, perception and function in plant development and stress responses," in Lipid Metabolism, pp. 393-442, InTech Europe, 2013. 
[73] L. Pauwels and A. Goossens, "The JAZ proteins: A crucial interface in the jasmonate signaling cascade," The Plant Cell, vol. 23, no. 9, pp. 3089-3100, 2011.

[74] H. Yoshikawa, C. Honda, and S. Kondo, "Effect of lowtemperature stress on abscisic acid, jasmonates, and polyamines in apples," Plant Growth Regulation, vol. 52, no. 3, pp. 199-206, 2007.

[75] M. S. Aghdam and S. Bodbodak, "Physiological and biochemical mechanisms regulating chilling tolerance in fruits and vegetables under postharvest salicylates and jasmonates treatments," Scientia Horticulturae, vol. 156, pp. 73-85, 2013.

[76] R. W. M. Fung, C. Y. Wang, D. L. Smith, K. C. Gross, Y. Tao, and M. Tian, "Characterization of alternative oxidase (AOX) gene expression in response to methyl salicylate and methyl jasmonate pre-treatment and low temperature in tomatoes," Journal of Plant Physiology, vol. 163, no. 10, pp. 1049-1060, 2006.

[77] R. Mittler, "Oxidative stress, antioxidants and stress tolerance," Trends in Plant Science, vol. 7, no. 9, pp. 405-410, 2002.

[78] M. Sharma and A. Laxmi, "Jasmonates: Emerging players in controlling temperature stress tolerance," Frontiers in Plant Science, vol. 6, no. 2016, article no. 1129, 2016.

[79] K. Kazan, "Diverse roles of jasmonates and ethylene in abiotic stress tolerance," Trends in Plant Science, vol. 20, no. 4, pp. 219229, 2015.

[80] J. Nakamura, T. Yuasa, T. T. Huong et al., "Rice homologs of inducer of CBF expression (OsiCE) are involved in cold acclimation," Plant Biotechnology Journal, vol. 28, no. 3, pp. 303309, 2011.

[81] K. Miura, H. Shiba, M. Ohta et al., "SlICE1 encoding a MYCtype transcription factor controls cold tolerance in tomato, Solanum lycopersicum," Plant Biotechnology Journal, vol. 29, no. 3, pp. 253-260, 2012.

[82] K. Miura, A. Sato, H. Shiba, S. W. Kang, H. Kamada, and H. Ezura, "Accumulation of antioxidants and antioxidant activity in tomato, Solanum lycopersicum, are enhanced by the transcription factor SIICE1," Plant Biotechnology Journal, vol. 29, no. 3, pp. 261-269, 2012.

[83] L. Liu, L. Duan, J. Zhang, Z. Zhang, G. Mi, and H. Ren, "Cucumber (Cucumis sativus L.) over-expressing cold-induced transcriptome regulator ICE1 exhibits changed morphological characters and enhances chilling tolerance," Scientia Horticulturae, vol. 124, no. 1, pp. 29-33, 2010.

[84] Y. Hu, L. Jiang, F. Wang, and D. Yu, "Jasmonate regulates the INDUCER OF CBF expression-C-repeat binding factor/dre binding factorl Cascade and freezing tolerance in Arabidopsis," The Plant Cell, vol. 25, no. 8, pp. 2907-2924, 2013.

[85] M. F. Thomashow, "Molecular basis of plant cold acclimation: Insights gained from studying the CBF cold response pathway," Plant Physiology, vol. 154, no. 2, pp. 571-577, 2010.

[86] H. Gustafsson, "Signal transduction during cold, salt, and drought stresses in plants," Molecular Biology Reports, vol. 39, no. 2, pp. 969-987, 2012.

[87] M. D. Groppa and M. P. Benavides, "Polyamines and abiotic stress: Recent advances," Amino Acids, vol. 34, no. 1, pp. 35-45, 2008.

[88] L. Z. Yadegari, R. Heidari, and J. Carapetian, "The influence of cold acclimation on proline, malondialdehyde (MDA), total protein and pigments contents in soybean (Glycine max) seedlings," Journal of Biological Sciences, vol. 7, no. 8, pp. 14361441, 2007.
[89] A. M. Kinnersley and F. J. Turano, "Gamma aminobutyric acid (GABA) and plant responses to stress," Critical Reviews in Plant Sciences, vol. 19, no. 6, pp. 479-509, 2000.

[90] H. Knight and M. R. Knight, "Abiotic stress signalling pathways: Specificity and cross-talk," Trends in Plant Science, vol. 6, no. 6, pp. 262-267, 2001.

[91] A. Polle, "Dissecting the superoxide dismutase-ascorbateglutathione-pathway in chloroplasts by metabolic modeling. Computer simulations as a step towards flux analysis," Plant Physiology, vol. 126, no. 1, pp. 445-462, 2001.

[92] A. Rawyler, D. Pavelic, C. Gianinazzi, J. Oberson, and R. Braendle, "Membrane lipid integrity relies on a threshold of ATP production rate in potato cell cultures submitted to anoxia," Plant Physiology, vol. 120, no. 1, pp. 293-300, 1999.

[93] J. Harwood, "Fatty Acid Metabolism," Annual Review of Plant Biology, vol. 39, no. 1, pp. 101-138.

[94] H. Ibolya, M. Gabriele, S. Alois, and et al., "Membrane-associated stress proteins: more than simply chaperones," Biochimica et Biophysica Acta (BBA)-Biomembranes, vol. 1778, no. 7, pp. 1653$1664,2008$.

[95] N. B. Gusev, N. V. Bogatcheva, and S. B. Marston, "Structure and properties of small heat shock proteins (sHsp) and their interaction with cytoskeleton proteins," Biochemistry, vol. 67, no. 5, pp. 511-519, 2002.

[96] Z.-G. Wu, W. Jiang, S.-L. Chen, N. Mantri, Z.-M. Tao, and C.-X. Jiang, "Insights from the cold transcriptome and metabolome of dendrobium officinale: Global reprogramming of metabolic and gene regulation networks during cold acclimation," Frontiers in Plant Science, vol. 7, no. 2016, article no. 1653, 2016.

[97] G.-T. Huang, S.-L. Ma, L.-P. Bai et al., "Signal transduction during cold, salt, and drought stresses in plants," Molecular Biology Reports, vol. 39, no. 2, pp. 969-987, 2012.

[98] A. Piers, H. Charlotte, K. Ewon, and et al., "The Arabidopsis mediator complex subunits MED16, MED14, and MED2 regulate mediator and RNA polymerase II recruitment to CBFresponsive cold-regulated genes," Plant Cell, vol. 26, no. 9, pp. 465-84, 2014. 


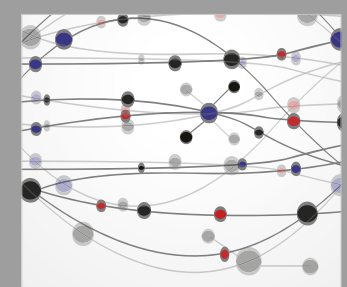

The Scientific World Journal
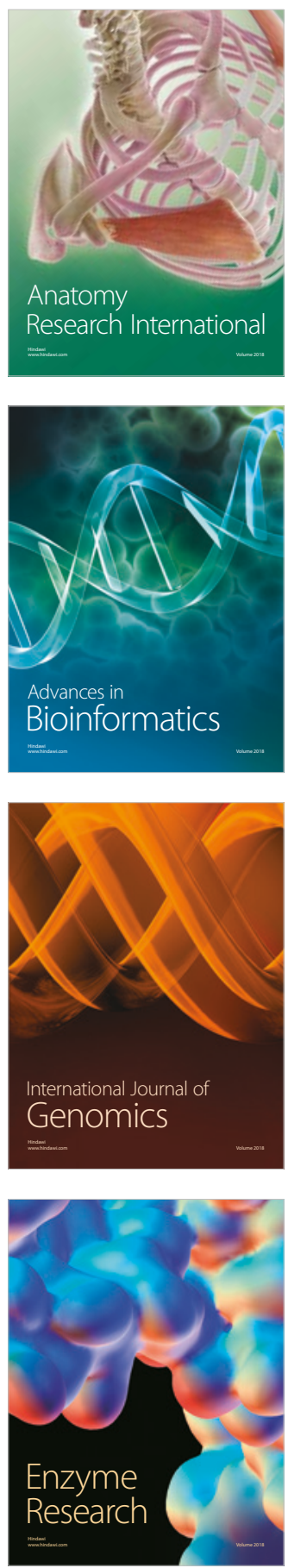
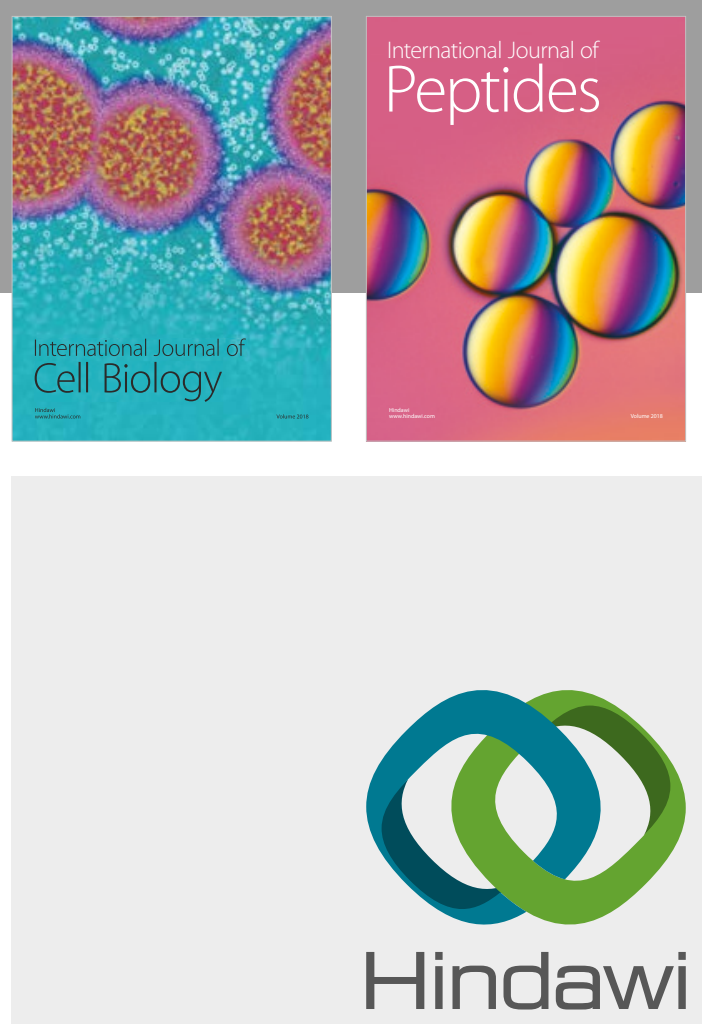

Submit your manuscripts at

www.hindawi.com
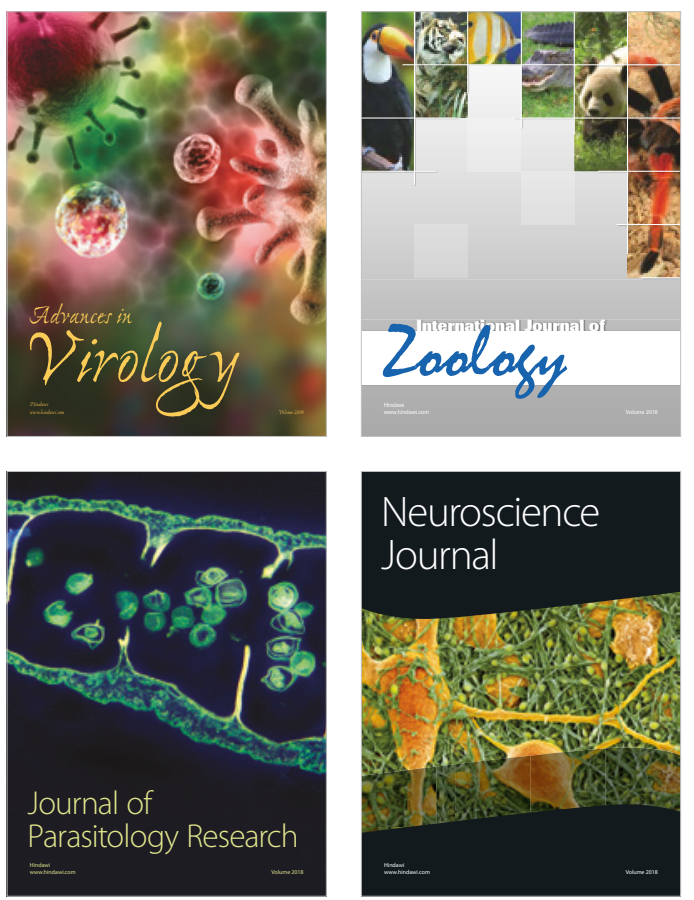
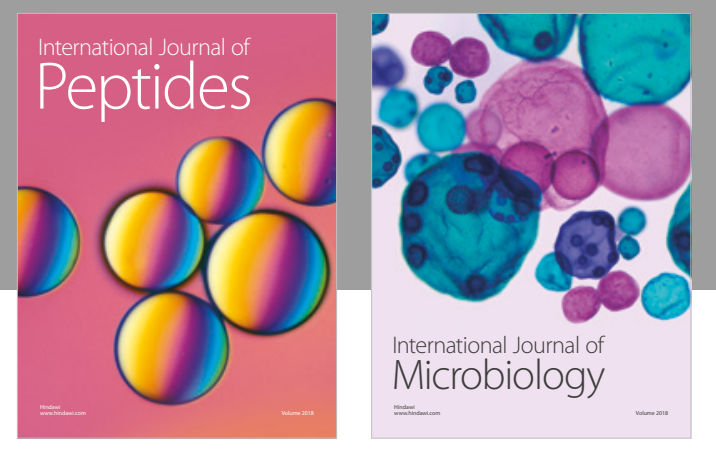

nternational Journal of Microbiology
Journal of
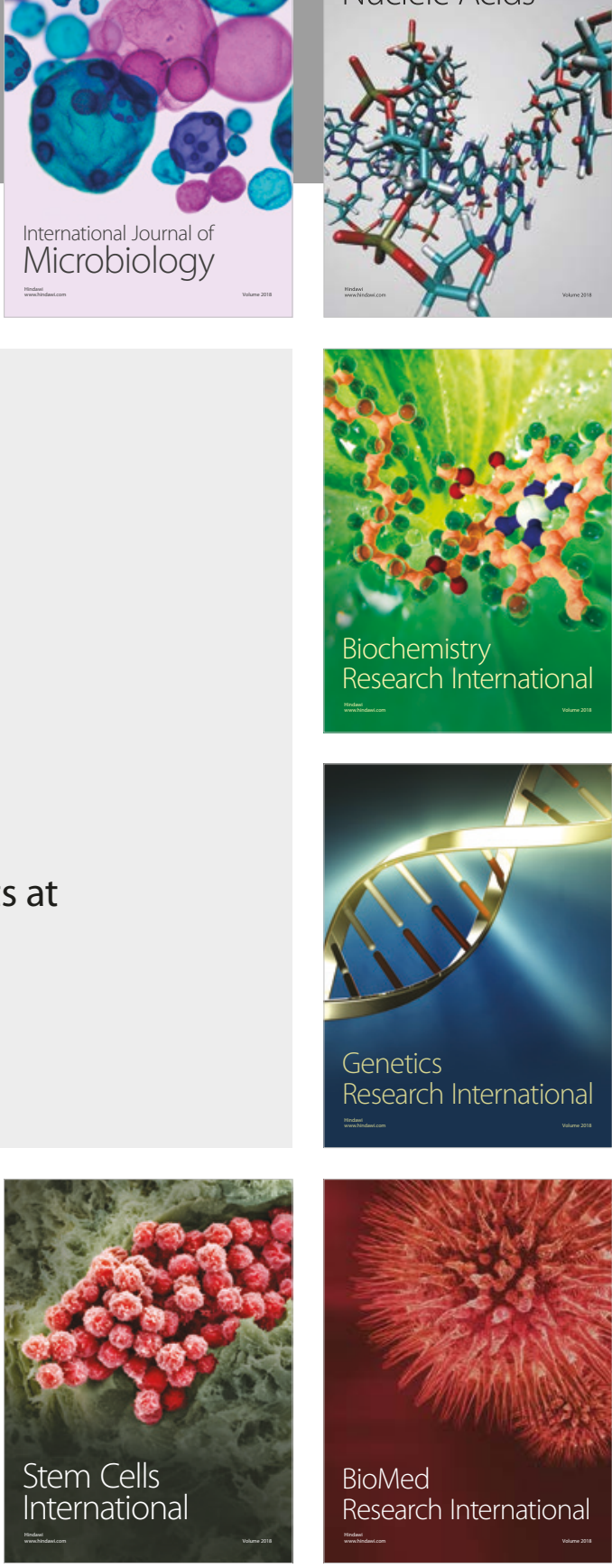
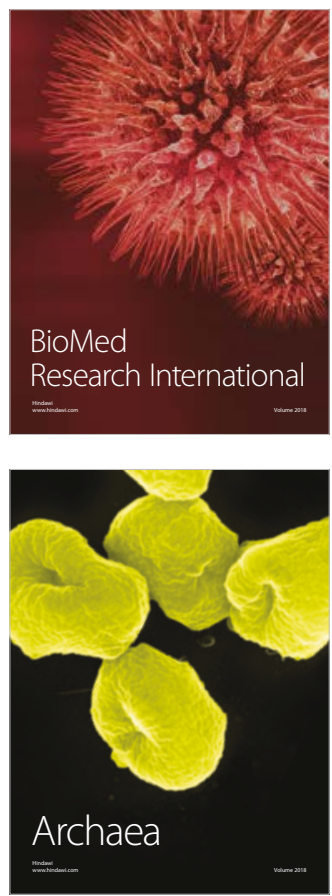